\title{
A comparative clinical and echocardiography study of acute myocardial infarction, patients above and below 40 years of age
}

\author{
Kumar Patel N. ${ }^{\mathbf{1}}$, Oram G. ${ }^{2}$, Kumar Bariha P. ${ }^{*}$ \\ DOI: https://doi.org/10.17511/ijmrr.2020.i06.06 \\ 1 Nayan Kumar Patel, Assistant Professor, Department of Cardiology, Veer Surendra Sai Institute Of Medical Sciences And Research, Burla, \\ Odisha, India. \\ 2 Gouri Oram, Assistant Professor, Veer Surendra Sai Institute Of Medical Sciences And Research, Burla, Odisha, India. \\ 3* Prafulla Kumar Bariha, Assistant Professor, Department of Medicine, Veer Surendra Sai Institute Of Medical Sciences And Research, \\ Burla, Odisha, India.
}

Background: Myocardial infarction is one of the major health problems in both developed and developing countries and is the leading cause of premature death among adults in developed countries while its incidence is on an increase in developing countries as well, including India. Objectives: To determine the prevalence of various risk factors in young AMI patients and to compare them with that of older patients. To compare the clinical presentation, course, and complications among both the groups. Methods: 60 AMI patients were taken into two groups younger and older according to age. For the diagnosis of AMI clinical criteria, ECG manifestations, cardiac biomarkers, and echocardiography criteria were taken into account. Risk factor analysis was done according to smoking habits, hypertension, lipid profile, diabetic Mellitus, obesity, and family history. All the parameters of both groups were compared and analyzed statistically. Results: AMI was found to have male preponderance with an M: F ratio of 9:1 and 3.4:1 in group I and II patients respectively. Smoking habit was found to be the commonest risk factors. Equal patients in each group had a TC/HDL-C ratio over 4.5. Anterior wall infarction was the commonest form of infraction in both Groups. Among the early complications, the occurrence of heart failure was found to be significantly higher in Group II patients. Conclusion: In the present study it is evident that the natural course, the extent of ventricular dysfunction, arrhythmias, wall motion abnormalities, mortality in acute myocardial infarction bears any similarity in both younger and older patient population; but not in all aspects.

Keywords: Coronary Artery Disease (CAD), Young AMI, Echocardiography in AMI

\section{Corresponding Author}

Prafulla Kumar Bariha, Assistant Professor, Department of Medicine, Veer Surendra Sai Institute Of Medical Sciences And Research, Burla, Odisha, India.

Email: drpkbariha@gmail.com
How to Cite this Article

To Browse

Patel NK, Oram G, Bariha PK. A comparative clinical and echocardiography study of acute myocardial infarction, patients above and below 40 years of age. Int J Med Res Rev. 2020;8(6):410-415. Available From https://ijmrr.medresearch.in/index.php/ijmrr/article/ view/1223

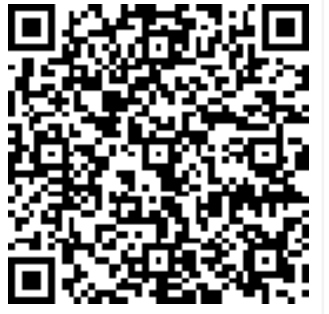

Review Round 1
2020-11-22
Funding
Nil




\section{Introduction}

Myocardial infarction is one of the major health problems in both developed and developing countries and is the leading cause of premature death among adults in developed countries while its incidence is on an increase in developing countries as well, including India. Coronary Artery Disease (CAD) in young $(<40$ years $)$ has aroused considerable interest in recent years. It is being recognized with increasing frequency. Several studies are available on the coronary angiographic profile and risk factors analysis of young patients with CAD from abroad Underwood DA et al, 1985 [1] and from India Jayachandran $R$ et al, 1987, Khalilulla M. 1983 [2].

The pathological changes underlying coronary artery disease begin in early childhood. These are further influenced by cigarette smoking, obesity, psychological stress, hypertension, blood lipids, dietary indiscretions, diabetes, and lower levels of physical activity Glover et al, 1982 [3]. Prevalence of smoking is significantly higher in younger age groups. Smoking appears to be the commonest risk factor in young in CAD Glover et al, 19823. Hypercholesterolemia and strong family history are the other denominators amongst these smoking is a stronger risk factor. Diabetes appears to be less common. Jayachandra et al found that obesity as a risk factor was present in $39 \%$. They further observed that at least 2 risk factors were present in $60 \%$ of patients. The prognosis and management of $C A D$ in young varies depending on the presence and absence of obstructive coronary atherosclerotic disease. Coronary angiography and left ventriculography are required for a definite assessment of the potential for revascularization.

\section{Materials and Methods}

Settings: The study was conducted in the department of General Medicine and Cardiology of VSS Institute of Medical Science and Research (VIMSAR), Burla, Odisha.

Duration and Study design: The study was conducted from April 2019 to March 2020. It was an Observational study.

Study subjects: Patients of Acute myocardial infarction (AMI), who attended the outpatient and inpatient wards of the Medicine and Cardiology department in VIMSAR, Burla were included in the study.
Sample size: Random sampling was considered in the study; as per this, 60 patients were included in this research.

Inclusion criteria: After hospitalization, a detailed clinical examination was done and recording of risk factors such as smoking, hypertension, diabetes, obesity, hypercholesterolemia, family history, and history of CAD along with necessary laboratory investigations were undertaken. Diagnosis of AMI was made basing on Clinical presentation, typical E.C.G. changes, Raised Serum cardiac enzyme essentially total CK or CK-MB presence of at least 2 of the above three criteria were taken as diagnostic features of acute myocardial infarction. Only those patients who satisfied these criteria were included in the study. Depending upon the age of the patients, all cases in the study were divided into two groups. Group-1: < 40 years of age (young) and Group- II: $>40$ years of age (elderly).

Ethical issue: The study was approved by the institutional ethics committee.

Methodology: The following investigations were done in all patients on admission and whenever required. ECG was done at the time of admission and repeated whenever required. Laboratory investigations: $\mathrm{Hb} \%, \mathrm{TLC}, \mathrm{DC}, \mathrm{ESR}$, Urine analysis, fasting blood sugar, Lipid Profile, Serum Urea, Creatinine, Total CK or CK-MB, Troponin I was done. Importance of Echocardiography in AMI has the following implication: Helps to know the extent of coronary artery disease, Wall motion abnormality has been used to prognosticate the outcome of myocardial infarction and helps in diagnosing non-Q infarction, L.V. aneurysms, Pericardial effusion, Intramural thrombus, Doppler Echocardiography helps to assess the severity of MR/TR and also used to estimate Cardiac output. Assessment of regional wall motion abnormalities by two-dimensional (2D) echocardiography, Evaluation of ejection fraction by M-mode echocardiography.

\section{Results}

Among 60 AMI patients out of which $20(33.3 \%)$ are below the age of 40 years and $40(60.3 \%)$ patients were above 40 years of age. The incidence of AMI in male patients is found to be higher than female but as the age increases the population of female AMI cases also increases, still a figure less than that of males. The Table- 1 showing various risk factors as smoking is found significantly in Group - I (65\%) and also Group - II (55\%) but a family history of 
IHD is found statistically higher in Group - I (40\%) in comparison to Group - II (10\%). At the same time obesity is also marked in elderly patients $(37.5 \%)$. So far the multiple risk factors are concerned it is almost the same in both the group as hypertension and DM are found to be in higher percentage in Group - II than Group - I.

Table-1: Risk factors in young versus old.

\begin{tabular}{|c|c|c|c|c|c|}
\hline \multirow[t]{2}{*}{ Risk Factors } & \multicolumn{2}{|c|}{ Group - I } & \multicolumn{2}{|c|}{ Group - II } & \multirow[t]{2}{*}{ P-Value } \\
\hline & No. & $\%$ & No. & $\%$ & \\
\hline Smoking & 13 & 65 & 22 & 55 & NS \\
\hline Hypertension & 3 & 15 & 9 & 22.5 & NS \\
\hline Diabetes Mellitus & 1 & 5 & 6 & 15 & NS \\
\hline Obesity & 3 & 15 & 15 & 37.5 & $\mid<0.01$ \\
\hline Family history of IHD & 8 & 40 & 4 & 10 & $<0.01$ \\
\hline Multiple Risk factors & 11 & 55 & 21 & 52.5 & NS \\
\hline
\end{tabular}

Though the incidence of cigarette smoking is found in both the groups but the number of cigarettes smoked per day is higher in Group-I ( $\leq 40$ years of age) ( $>20$ cigarette $-45 \%$ ) than Group-II ( $>40 \mathrm{yrs}$ of age) ( $>20$ cigarettes- $17.5 \%)$ which is statistically significant. There is a significant difference in the number of risk factors in both the groups though multiple risk factors do not show any difference among them. 2 risk factors found in Group-I is 50\% whereas, in Group-II, $42.3 \%$ and no risk factor is found in minimum in Group-I (5\%) in comparison to Group-II where it is higher (22.5\%) and 1 risk factor in Group-I (40\%) than Group- II $(25 \%)$. No significant difference in lipid profile was found when both the groups were compared.

Table-2 shows the coronary risk according to TC/HDL-C ratios as per Helsinki Scale. No significant difference was found in both groups when compared. Patients belonging to moderate and high risk i.e. TC/HDL-C > 4.5 constituted $65 \%$ each in both groups.

Table-2: Cardiovascular risk according to TC/HDL-C.

\begin{tabular}{|l|l|l|l|}
\hline \multirow{2}{*}{ Risk } & \multicolumn{2}{|c|}{ Number of Cases } & \multirow{2}{*}{ P-value } \\
\cline { 2 - 3 } & Group - I & Group - II & \\
\hline Normal <4.5 & $7(35 \%)$ & $14(35 \%)$ & $>0.05$ \\
\hline Moderate Risk (4.5-6.5) & $8(40 \%)$ & $17(42.5 \%)$ & $>0.05$ \\
\hline High Risk $(>6.5)$ & $5(25 \%)$ & $9(22.5 \%)$ & $>0.05$ \\
\hline
\end{tabular}

The history of IHD (AMI and Angina) was found to be significantly higher in Group - II (32.5\%) in comparison to Group - I (10\%). No. significant difference was found in both the groups but typical presentation with chest pain is common to both groups (90\%) in Group I and (82.5\%) in Group II.
No significant difference was found in sweating, pain abdomen, nausea, vomiting, and syncope, but dyspnoea was found in Group - II (37.5\%) as compared to $(10 \%)$ in Group - I patients which are statistically significant.

Table-3: Other symptoms at presentation in both the groups.

\begin{tabular}{|c|c|c|c|c|c|}
\hline \multirow[t]{2}{*}{ Feature } & \multicolumn{2}{|c|}{ Group : } & \multicolumn{2}{|c|}{1 Group II } & \multirow[t]{2}{*}{ P-value } \\
\hline & No. & $\%$ & No. & $\%$ & \\
\hline Sweating & 13 & 65 & 28 & 70 & $>0.05$ \\
\hline Plain abdomen and / or nausea and vomiting & 2 & 25 & 8 & 20 & $>0.05$ \\
\hline Syncope & 2 & 10 & 5 & $12-5$ & $>0.05$ \\
\hline Dysponea & 2 & 10 & 15 & 37.5 & $<0.01$ \\
\hline
\end{tabular}

Anterior wall infarction is found to be the commonest in both the groups (Group - I, 60\%), (Group - II, 50\%). In the young Anterior wall, AMI is most common (60\%) and multiple infarcts were not found in the study whereas in Group II multiple infarcts were found in $7.5 \%$ of cases. There is no significant difference observed in the overall incidence of arrhythmia and conduction defects. However, VPC in Group-I (5\%) is less than Group II $(15 \%)$, and RBBB and LBBB were found to be $(7.5 \%)$ in Group-I and $2.5 \%$ respectively. The incidence of heart failure observed in Group - II $(25.5 \%)$ is significantly higher than in Group - I (5\%) LVF is more common in Group - II (20\%) than in Group - I (5\%).

No significant difference was found in ejection fraction in both the groups. However, the percentage of patients showing dysfunction in Group- I is $50 \%$ whereas in Group- II it is $60 \%$. The anterior segment motion abnormality was most common in both groups i.e. $30 \%$ in Group - I and $40 \%$ in Group - II. No wall motion abnormally could be detected in $30 \%$ of young AMI patients while only $2.5 \%$ of Group - II patients had this feature. About $5 \%$ of young AMI patients died during early hospitalization in contrast to $15 \%$ of old AMI patients. However, there is no statistical significance $(P>0.05)$.

\section{Discussion}

On analysis of age distribution of AMI cases, it was found that the incidence increased from $2(10 \%)$ cases in the age group of $26-30$ years to $13(65 \%)$ cases in the age group of 36 to 40 years of age amongst 20 young AMI cases. None of the young AMI cases below 35 years of age was female while as a whole only $2(10 \%)$ cases of young AMI cases were of the female sex. 
Among AMI cases above 40 years of age, the no of cases above 55 years of age rose from $6(15 \%)$ in the age range of $41-45$ years of age to $17(28.4 \%)$ in patients. Such a progressive rise in the incidence of AMI with age in both the groups could be due to the prevalence of atherosclerosis which is the single most important determinant or cause of coronary heart disease.

However, investigators have suggested that obesity is not a major risk factor for the development of AMI $[4,5]$ The prevalence of other risk factors such as hypertension and diabetes mellitus did not differ significantly in the present series $(P>0.05)$.

In the present series also, the incidence of hypertension in older AMI patients was slightly more i.e. $22.5 \%$ than that is seen amongst younger patients i.e. $15 \%$. Such a low incidence of hypertension before the development of AMI was noted in other studies [6].

In the present study in $55 \%$ and $52.5 \%$ of Younger and older AMI patients respectively, two or more risk factors were identified. No risk factor could be detected in $5 \%$ of younger patients while $22.5 \%$ of older patients had non-association with a risk factor. Several studies have documented that CAD patients are burdened with multiple risk factors. Dolder and Oliver have reported the prevalence of multiple risk factors in young patients with AMI as $41 \%$ Gohlke et al [7] found that $75 \%$ had multiple risk factors while $>1 \%$ had no risk factor.

Analysis and comparison of lipid profiles in younger and elderly patients in the present series yielded no significant difference $(P>0.05)$ for all the parameters including total cholesterol, TG, HDL-C, VLDL - C, and T-C/HDL C ratio. Anterior myocardial infarction was the commonest in both groups to be followed by inferior myocardial infarction. Also, there was no significant difference, in the site of infarction among both the groups (>0.05). In their series 44 of 60 young and 34 of 60 older AMI patients had anterior AMI while corresponding figures for interior myocardial infarction were seen only in $7.5 \%$ cases of older MI patients in the present series while none in the younger group had multiple infarctions.

In the present series, none of the younger patients and only one $(2.5 \%)$ old patient had evidence of subendocardial infarction. But in contrast, a higher incidence $(23-27 \%)$ of subendocardial infarction has been more frequently described in young patients Virmani and Me. Allister [8].
In the present study, no significant differences $(P>0.05)$ in clinical presentations and associated symptoms were observed, except for the incidence of dyspnoea which was seen in a significantly higher percentage of older patients $(p>0.01)$. The incidence of pain in young patients in the present series is similar to the observations of Gertler and white [9]. The early clinical course of young patients may favorably differ from older patients given a smaller incidence of complications such as cardiac decompensation, arrhythmias conduction defects, cardiogenic shock, pericarditis thromboembolic phenomenon, and mitral regurgitation. The incidence of postinfarction angina was identical i.e. $10 \%$ in both the group. But on the statistical comparison, it was revealed that only the incidence of cardiac failure was significantly high $(p<0.01)$ in the older patient group whereas in the case of other complications no significant statistical difference could be obtained. A similar result was also found by Uhi and Farrel [10].

A more detailed analysis of arrhythmias in the present study revealed no significant difference $(P>0.05)$ in the incidences of tachyarrythmias and conduction defects. Life-threatening VF and VT were present in $10 \%$ of patients of the population in each group while $5 \%$ of young patients and $15 \%$ of older patients had ventricular premature beats. In the present series conduction defects such as 1st degree, 2nd degree, and complete heart block were found in $5 \%, 10 \%$, and $15 \%$ and $7.5 \%$ and $7.5 \%$ and $15 \%$ of young and older patients population respectively. No significant difference in incidences was noted. Very low but significant differences in the incidence of interventricular conduction defects were observed between two groups i.e. $10 \%$ had such complications, which is similar to the description given by Mufflris and Atkins [11].

In the present series during the observation period, $5 \%$ of young patients and $15 \%$ of older patients died in the hospital. There was no significant difference in early mortality rate in these two groups ( $p>0.05)$. Garg et al [12] have noted $6.6 \%$ and $15 \%$ mortality in younger and older patient groups respectively.

\section{Limitation}

The present study was a small study with only 60 AMI patients. Because our hospital set up has a limited facility for primary PCI for which angiographic correlation of AMI patients could not be done. 
Most patients were managed conservatively. Due to a lack of awareness among the public about chest pain, many patients presented late to the hospital which hindered early management and increased morbidity and mortality.

\section{Conclusion}

Myocardial infarction in younger age groups largely simulates myocardial infarction in older groups barring a few features such as sex predilection, association with the smoking pattern, family history of CAD, obesity, and association with heart failures.

Younger patients do have a less incidence of AMI in females while they constitute a significantly higher percentage of heavy smokers i.e. smoking $\geq 20$ cigarettes/day, and also more patients with a family history of CAD when compared with their older counterparts. Obesity is significantly more prevalent amongst older patients who also exhibit a greater propensity for the development of heart failure.

History of IHD in past is also more common in older patients. The association of the risk factors. i.e., hypertension, diabetes, Mellitus, lipid abnormalities, and complications including compromisation of ejection fraction as well as motion abnormality do not differ significantly in both the groups.

\section{What does the study add to the existing knowledge?}

Contrary to previous belief AMI is quite common among younger patients ( $<40$ years) and most young patients are heavy smokers and have a family history of CAD. So regular cardiac checkups in young patients having risk factors will be beneficial in preventing the development of CAD and AMI.

\section{Author's Contribution}

Dr. Nayan Kumar Patel: Helped in the diagnosis and management of AMI patients, data collection, and manuscript preparation.

Dr. Gouri Oram: Data collection, analysis, and manuscript preparation

Dr. Prafulla Kumar Bariha: Data collection, analysis, and manuscript preparation

\section{Acknowledgements}

The authors would like to thank their patients for their adherence and kind cooperation in this study and the staff and technicians of the central laboratory for performing the different tests in the study.

\section{Reference}

01. Underwood DA, Proudfit WL, Lim J, MacMillan JP. Symptomatic coronary artery disease in patients aged 21 to 30 years. Am J Cardiol. $1985 ; 55(6) 631-634$.

doi: $\quad 10.1016 / 0002-9149(85) 90126-2 \quad$ [Crossref]

02. Khalilulla M. Coronary artery disease- the angiographic profile. Indian Heart $\mathrm{J}$. 1983;35(4)197-199. doi: $10.1016 /$ j.ihj.2012.07.001 [Crossref]

03. Glover MU, Kuber MT, Warren SE, Vieweg WV. Myocardial infarction before age 36- risk factor and arteriographic analysis. Am J Cardiol. 1982;49(7)1600-1603.

doi: $\quad 10.1016 / 0002-9149(82) 90234-X \quad$ [Crossref]

04. Bergstrand R, Vedin A, Wilhelmsson C, Wallin J, Wedel $\mathrm{H}$, Wilhelmsen L. Myocardial infarction among men below age 40 . Heart. $1978 ; 40(7) 783-788$.

doi: $10.1136 /$ hrt.40.7.783 [Crossref]

05. Truett J, Cornfield J, Kannel W. A multivariate analysis of the risk of coronary heart disease in Framingham. J Chronic Dis. 1967;20(7)511524.

doi: $\quad 10.1016 / 0021-9681(67) 90082-3 \quad$ [Crossref]

06. Pahlajani DB, Chawla MH, Kapashi KA. Coronary artery disease pattern in the young. J Assoc Physician India. 1989;37(5)312-314.

[Crossref]

07. Gohlke H, Stürzenhofecker $P$, Thilo A, Droste $C$, Görnandt L, Roskamm H. Coronary angiographic findings and risk factors in post infarction patients under the age of 40, In Myocardial infarction at young age. Springer, Berlin, Heidelberg. 1981;61-77.

doi: 10.1007/978-3-642-68294-0_10 [Crossref] 
08. Virmani R, Mc Allister HA. "Myocardial infarction at young age". Ed H Roskamm. 1981;92-103.

doi: 10.1007/978-3-642-68294-0_13 [Crossref]

09. Gertler and white. Coronary Heart Disease in Young Adults. Science. 1954;120(3125)835836.

doi: $\quad 10.1126 /$ science.120.3125.835-a $\quad$ [Crossref]

10. Uhl GS, Farrell PW. Myocardial infarction in young adults- risk factors and natural history. Am Heart J. 1983;105(4)548-553.

doi: $\quad 10.1016 / 0002-8703(83) 90476-3 \quad$ [Crossref]
11. Atkins JM, Matthews $O A$, Blomqvist CG, Mullins $\mathrm{CB}$. Incidence of arrhythmias induced by isometric and dynamic exercise. Heart. 1976; May 1;38(5)465-471.

doi: $10.1136 /$ hrt.38.5.465 [Crossref]

12. Garg $R$, Yusuf $S$, Bussmann WD, Sleight $P$, Uprichard A, Massie B, et al. Overview of randomized trials of angiotensin-converting enzyme inhibitors on mortality and morbidity in patients with heart failure. Jama. 1995 May $10 ; 273(18) 1450-1456$.

doi: $10.1001 /$ jama.1995.03520420066040 [Crossref] 